Check for updates

Cite this: J. Mater. Chem. A, 2017, 5, 15105

Received 7th March 2017

Accepted 3rd July 2017

DOI: $10.1039 / \mathrm{c} 7 \mathrm{ta0} 2081 \mathrm{c}$

rsc.li/materials-a

\section{Design principles of perovskites for solar-driven thermochemical splitting of $\mathrm{CO}_{2} \dagger$}

\author{
Miriam Ezbiri, Michael Takacs, Boris Stolz, Jeffrey Lungthok, Aldo Steinfeld if \\ and Ronald Michalsky (D)*
}

Perovskites are attractive redox materials for thermo/electrochemical fuel synthesis. To design perovskites with balanced redox energetics for thermochemically splitting $\mathrm{CO}_{2}$, the activity of lattice oxygen vacancies and stability against crystal phase changes and detrimental carbonate formation are predicted for a representative range of perovskites by electronic structure computations. Systematic trends in these materials properties when doping with selected metal cations are described in the free energy range defined for isothermal and temperature-swing redox cycles. To confirm that the predicted materials properties root in the bulk chemical composition, selected perovskites are synthesized and characterized by X-ray diffraction, transmission electron microscopy, and thermogravimetric analysis. On one hand, due to the oxidation equilibrium, none of the investigated compositions outperforms non-stoichiometric ceria - the benchmark redox material for $\mathrm{CO}_{2}$ splitting with temperature-swings in the range of $800-$ $1500{ }^{\circ} \mathrm{C}$. On the other hand, certain promising perovskites remain redox-active at relatively low oxide reduction temperatures at which ceria is redox-inactive. This trade-off in the redox energetics is established for $\mathrm{YFeO}_{3}, \mathrm{YCO}_{0.5} \mathrm{Fe}_{0.5} \mathrm{O}_{3}$ and $\mathrm{LaFe}_{0.5} \mathrm{Ni}_{0.5} \mathrm{O}_{3}$, identified as stable against phase changes and capable to convert $\mathrm{CO}_{2}$ to $\mathrm{CO}$ at $600{ }^{\circ} \mathrm{C}$ and $10 \mathrm{mbar} \mathrm{CO}$ in $\mathrm{CO}_{2}$, and to being decomposed at $1400^{\circ} \mathrm{C}$ and $0.1 \mathrm{mbar}_{2}$ with an enthalpy change of $440-630 \mathrm{~kJ} \mathrm{~mol}^{-1} \mathrm{O}_{2}$.

\section{Introduction}

The solar-driven thermochemical splitting of $\mathrm{CO}_{2}$ into $\mathrm{CO}$ and $\mathrm{O}_{2}$ operates at high temperatures and utilizes the entire solar spectrum and, thus, can potentially yield high solar-to-fuel energy conversion efficiencies. ${ }^{\mathbf{1 - 1 1}}$ It can be realized by a 2-step redox cycle, comprising the endothermic reduction of the metal oxide yielding $\mathrm{O}_{2}$, followed by the exothermic oxidation of a metal oxide with $\mathrm{CO}_{2}$ yielding $\mathrm{CO}$. This is shown schematically in Fig. 1a for perovskite-type metal oxides of $\mathrm{ABO}_{3}$ stoichiometry, with $\mathrm{A}$ and $\mathrm{B}$ representing metals at the twelve- and six-fold coordinated crystal lattice sites, respectively. Given its crystallographic stability, favorable oxidation thermodynamics, and fast fuel production kinetics, nonstoichiometric ceria $\left(\mathrm{CeO}_{2-\delta}\right)$ has emerged as the benchmark redox material for the thermochemical splitting of $\mathrm{CO}_{2}$ and $\mathrm{H}_{2} \mathrm{O} .^{3,5,12-23}$ The use of $\mathrm{CeO}_{2-\delta}$ is however limited to solar reactors that can withstand the relatively high temperatures required for accessing moderate oxygen exchange capacities. Even at $1723 \mathrm{~K}$ and an oxygen partial pressures $p_{\mathrm{O}_{2}}$ below $10^{-3}$ bar $\mathrm{O}_{2}$, oxygen nonstoichiometries $\delta$ remain typically below $0.03 .^{3,6,24,25}$ To

Department of Mechanical and Process Engineering, ETH Zürich, 8092 Zürich, Switzerland.E-mail: michalskyr@ethz.ch

$\dagger$ Electronic supplementary information (ESI) available. See DOI: 10.1039/c7ta02081c circumvent these limitations, perovskites have recently attracted attention as an alternative class of redox materials with possibly higher oxygen nonstoichiometries and typically high oxygen vacancy conductivities..$^{5,24,26-38}$ The vast number of possible metal cation combinations in the perovskite structure may allow for control over the temperature and $p_{\mathrm{O}_{2}}$ requirements of the redox cycle.

Previous experimental studies with perovskites have focused mostly on lanthanum manganites. ${ }^{\mathbf{2 4 , 2 6 - 2 8 , 3 0 - 3 3}}$ For instance, McDaniel et al. ${ }^{24}$ demonstrated that reduction of $\mathrm{La}_{0.6} \mathrm{Sr}_{0.4^{-}}$ $\mathrm{Mn}_{0.6} \mathrm{Al}_{0.4} \mathrm{O}_{3-\delta}$ at $1623 \mathrm{~K}$ and $0.2 \mathrm{mbar}^{\mathrm{O}}$ and re-oxidation at $1273 \mathrm{~K}$ under 40 vol\% $\mathrm{H}_{2} \mathrm{O}$ or $\mathrm{CO}_{2}$ in Ar results in nine or six times greater $\mathrm{H}_{2}$ and $\mathrm{CO}$ yields, respectively, relative to ceria. ${ }^{24}$ Analogously, Takacs et al. ${ }^{32}$ showed that $\mathrm{La}_{0.6} \mathrm{Ca}_{0.4} \mathrm{Mn}_{0.6} \mathrm{Al}_{0.4^{-}}$ $\mathrm{O}_{3-\delta}$ reduced at $1700 \mathrm{~K}$ and $10^{-3}$ bar $\mathrm{O}_{2}$ releases up to five times more $\mathrm{O}_{2}$ per unit mass of redox material relative to ceria. However, the authors highlighted that although the reduction extents of the tested perovskites are higher than those of $\mathrm{CeO}_{2-\delta}$, oxidation extents with $\mathrm{H}_{2} \mathrm{O}$ and $\mathrm{CO}_{2}$ are lower. ${ }^{32}$ Choosing appropriate reduction and oxidation operating conditions for optimal performance is complicate since the thermodynamics and kinetics vary strongly with temperature, pressure, and the composition of the redox material. ${ }^{32,33}$ Furthermore, given the vast amount of possible materials compositions, experimental evaluation of metal oxide redox materials is limited by trial-and-error. 
A computational approach to the design of metal oxide redox materials was presented by Emery et al., ${ }^{39}$ calculating the thermodynamic stability and the oxygen vacancy formation energy for 5329 cubic and distorted $\mathrm{ABO}_{3}$ perovskites via high-throughput density functional theory (HT-DFT). The stability of a perovskite was calculated by subtracting the convex hull energy for $\mathrm{ABO}_{3}$ from the DFT-computed formation enthalpy of the perovskite, defined as the energy difference between the total energy of the $\mathrm{ABO}_{3}$ structure and the chemical potentials of A, B and oxygen. ${ }^{39}$ With this approach, the authors identified 139 compositions suitable for water splitting, such as $\mathrm{CeCoO}_{3}$ and $\mathrm{BiVO}_{3} \cdot{ }^{39}$ Other computational screening efforts for perovskite redox materials include the works by Deml et al., ${ }^{\mathbf{4 0 , 4 1}}$ correlating the oxygen vacancy formation energy, the enthalpy of metal oxide formation, and the position of the band gap for binary (one cation-type oxides) and ternary systems (with two cations, such as perovskites). Michalsky et $a l^{42}$ quantified scaling of the free energy and enthalpy of bulk metal oxide formation with the free energy of forming oxygen vacancies at the surface across various metal oxide structures, including three selected perovskites. Furthermore, Calle-Vallejo et al. ${ }^{43}$ computed perovskite bulk formation energies using DFT and Meredig et al. ${ }^{44}$ showed that a low enthalpy of reduction and a large positive entropy of reduction of the solid bulk metal oxide are thermodynamically favorable for two-step thermochemical splitting of $\mathrm{CO}_{2}$ and $\mathrm{H}_{2} \mathrm{O}$. Noteworthy, Curnan et al. $^{45}$ showed that the oxygen vacancies formation across $\mathrm{LaBO}_{3}, \mathrm{SrBO}_{3},(\mathrm{~B}=3 \mathrm{~d}$ transition metals $)$ and similar materials is thermodynamically more favorable in perovskite models with larger unit cell size. ${ }^{45}$ The energetics of the oxygen vacancy formation are found less favorable in the non-cubic perovskites. $^{45}$

a)
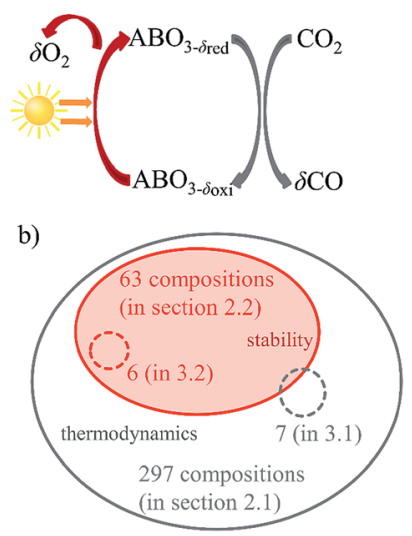

Fig. 1 (a) Schematic representation of two-step solar-driven thermochemical splitting of $\mathrm{CO}_{2}$ with nonstoichiometric perovskite redox materials. The oxygen nonstoichiometry after reduction and oxidation is denoted $\delta_{\text {red }}$ and $\delta_{\text {ox }}$, respectively. These define the oxygen exchange capacity, $\Delta \delta=\delta_{\text {red }}-\delta_{\text {ox }}$, which is equivalent to the specific fuel yield per redox cycle. (b) Schematic illustration of the number of computed (solid lines) and experimentally evaluated (dashed lines) perovskite compositions with respect to their thermodynamic properties (grey) and thermochemical stability (orange) discussed in the specified section of this article.
The present work screens perovskites for thermochemical $\mathrm{CO}_{2}$ splitting by: (1) choosing process conditions for perovskite reduction and oxidation comparable to those used for state-ofthe-art ceria based materials; (2) computing the thermochemical stability of cubic perovskites relative to that of possibly formed binary metal oxides and metal carbonates; (3) expanding the range of screened perovskites generally to quinternary compositions; and (4) validating the computed trends in the redox activity and thermochemical stability for selected compositions experimentally. DFT is used to screen $\mathrm{ABO}_{3}$, $\mathrm{AA}^{\prime} \mathrm{BO}_{3}, \quad \mathrm{ABB}^{\prime} \mathrm{O}_{3}$ and $\mathrm{AA}^{\prime} \mathrm{BB}^{\prime} \mathrm{O}_{3}$ perovskites for two-step temperature-swing and isothermal thermochemical splitting of $\mathrm{CO}_{2}$ splitting. We considered combinations of non-toxic, inexpensive, and stable metals at the twelve-fold $\left(\mathrm{A}, \mathrm{A}^{\prime}=\mathrm{Mg}\right.$, $\mathrm{Ca}, \mathrm{Sr}, \mathrm{Ba}, \mathrm{Y}, \mathrm{La}, \mathrm{Ce}$ ) and six-fold (B, $\mathrm{B}^{\prime}=\mathrm{Ti}, \mathrm{Cr}, \mathrm{Mn}, \mathrm{Fe}, \mathrm{Co}, \mathrm{Ni}$, $\mathrm{Cu}, \mathrm{Zr}, \mathrm{Al}$ ) coordinated crystal lattice sites. As a guide, Fig. 1b illustrates which set or subset of perovskite compositions was chosen in a specific section of this article for computational screening (orange) and experimental evaluation (grey), respectively.

\section{Electronic structure trends of perovskites}

\subsection{Redox activity}

The redox energetics of 297 perovskites were computed for the thermochemical splitting of $\mathrm{CO}_{2}$, of which 63 compositions had basic ternary $\mathrm{ABO}_{3}$ stoichiometry, while the 77, 67, and 90 compositions contained metal cation dopants at the $\mathrm{A}$ and/or $\mathrm{B}$ lattice sites resulting in $\mathrm{AA}^{\prime} \mathrm{BO}_{3}, \mathrm{ABB}^{\prime} \mathrm{O}_{3}$, and $\mathrm{AA}^{\prime} \mathrm{BB}^{\prime} \mathrm{O}_{3}$ stoichiometry, respectively. Fig. 2 shows the tendency of the most stable surfaces with (010) geometry to contain a specific Bcation, as an example for perovskites containing either $\mathrm{Ca}$ and Sr ( $c f$. Fig. 2a) or Ce and La ( $c f$. Fig. 2b) at the A-site, respectively.
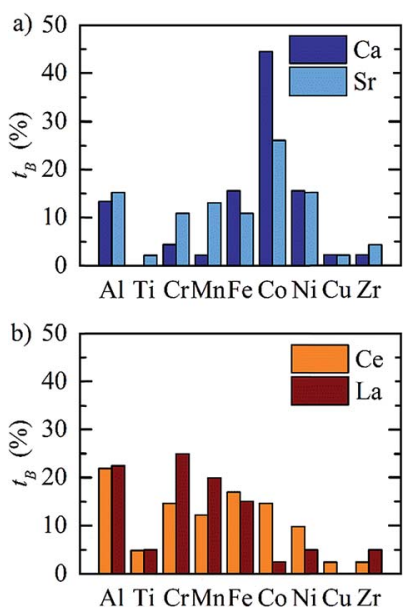

Fig. 2 Tendency of the most stable perovskite surfaces with (010) geometry and with (a) $\mathrm{Ca}$ (dark blue) and Sr (light blue), and (b) $\mathrm{Ce}$ (orange) and $\mathrm{La}$ (red) at the A-site to contain a specific metal at the Bsite (indicated on the $x$-axis), defined as $t_{B}=$ (number of most stable surfaces containing the specified $B$ cation)/(number of all surfaces containing the same A cation) $\times 100 \%$. 
As a trend, we find that surfaces containing alkaline earth metals at the A-site ( $c f$. Fig. 2a) frequently contain B-cations with intermediate periodic number, those with lanthanides at the Asite ( $c f$. Fig. 2b) more frequently contain B-cations with relatively low periodic number.

Making use of scaling relations for the free energy of forming oxygen vacancies at metal oxide surfaces, $\Delta G_{\mathrm{v}}[\mathrm{O}]$, and the free energy and enthalpy of bulk metal oxide formation, ${ }^{\mathbf{4 2}}$ we determined the Gibbs free energy changes for bulk perovskite reduction (liberating $\mathrm{O}_{2}$ ) and oxidation (reducing $\mathrm{CO}_{2}$ into $\mathrm{CO}$ ). Generally, the more endergonic reaction limits the oxygen exchange capacity of a perovskite. ${ }^{46}$ Fig. 3 shows the limiting free energy change of a $\mathrm{CO}_{2}$-splitting cycle $\left(\Delta \bar{g}_{\mathrm{O}_{2, \text { lim }}}^{\circ}\right.$, at process conditions) as a function of the standard partial molar enthalpy change for metal oxide reduction $\left(\Delta \bar{h}_{\mathrm{O}_{2}}^{\circ}\right.$, at ambient conditions), estimated as the reaction of perovskites into their brownmillerite analogs and $\mathrm{O}_{2}$. With other words, we employ the enthalpy change for metal oxide reduction, a measure of the bulk metaloxygen bond strength, as a single general descriptor of the application-specific redox energetics. Given the resulting volcano-type curve for metal oxide redox materials, ${ }^{42}$ we find the materials with the least-endergonic limiting free energy changes at the intersection of both correlations. Dependent on reaction temperatures and pressures, balance of the redox
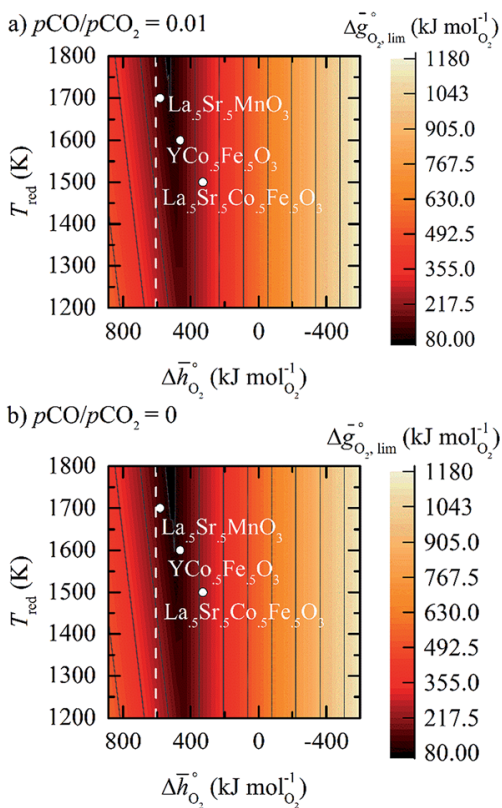

Fig. 3 Limiting standard partial molar Gibbs free energy for thermochemical splitting of $\mathrm{CO}_{2}\left(\Delta \bar{g}_{\mathrm{O}_{2 . \text { lim }}}^{\circ}\right)$ as a function of the metal oxide reduction temperature $\left(T_{\text {red }}\right)$ and the standard partial molar enthalpy of metal oxide reduction $\left(\Delta \bar{h}_{\mathrm{O}_{2}}\right)$. Oxide reduction is shown always at $p_{\mathrm{O}_{2}}$ $=10^{-4}$ bar, while oxide oxidation is always at a temperature $\left(T_{\mathrm{Ox}}\right)$ of $900 \mathrm{~K}$ and (a) $p_{\mathrm{CO}} / p_{\mathrm{CO}_{2}}=0.01$ (that is, $1 \% \mathrm{CO}$ in $\mathrm{CO}_{2}$ ), and (b) $p_{\mathrm{CO}} / p_{\mathrm{CO}_{2}}$ $=0$ (that is, $100 \% \mathrm{CO}_{2}$ ). $\mathrm{La}_{0.5} \mathrm{Sr}_{0.5} \mathrm{Co}_{0.5} \mathrm{Fe}_{0.5} \mathrm{O}_{3}, \mathrm{YCO}_{0.5} \mathrm{Fe}_{0.5} \mathrm{O}_{3}$, and $\mathrm{La}_{0.5} \mathrm{Sr}_{0.5} \mathrm{MnO}_{3}$ are displayed at $T_{\text {red }}$ of 1500,1600 and $1700 \mathrm{~K}$, respectively. For reference, the position of $\mathrm{CeO}_{2-\delta}$ is computed for the reduction of the $\mathrm{CeO}_{2}(111)$ facet yielding stable oxygen vacancies in the subsurface of $\mathrm{CeO}_{1.75}(111)$ and $\mathrm{O}_{2}$, indicated with dashed lines at $\Delta \bar{h}_{\mathrm{O}_{2}}^{\circ}$ of $606 \mathrm{~kJ} \mathrm{~mol}_{2}{ }^{-1}$. energetics indicates a favorable intermediately strong binding of oxygen, that is, strong enough to facilitate oxide oxidation but weak enough to allow for reduction of the oxidized oxide. Ideally, this intersection is located in the exergonic reaction space. To approach this, Fig. 3 shows the redox energetics at reasonable process conditions, that is, oxide reduction between 1200 and $1800 \mathrm{~K}$ and $10^{-4}$ bar $\mathrm{O}_{2}$ and oxide oxidation at $900 \mathrm{~K}$ in an atmosphere of either $1 \% \mathrm{CO}$ in $\mathrm{CO}_{2}$ (Fig. 3a) or $100 \% \mathrm{CO}_{2}$ (Fig. 3b). For the following discussion, the positions of $\mathrm{YCo}_{0.5^{-}}$ $\mathrm{Fe}_{0.5} \mathrm{O}_{3}, \mathrm{La}_{0.5} \mathrm{Sr}_{0.5} \mathrm{Co}_{0.5} \mathrm{Fe}_{0.5} \mathrm{O}_{3}$ and $\mathrm{La}_{0.5} \mathrm{Sr}_{0.5} \mathrm{MnO}_{3}$ are marked along with the position of $\mathrm{CeO}_{2-\delta}$ as a reference. As indicated by their position relative to the top of the volcano-type curve, yields of redox cycles using $\mathrm{YCo}_{0.5} \mathrm{Fe}_{0.5} \mathrm{O}_{3}$ and $\mathrm{La}_{0.5} \mathrm{Sr}_{0.5} \mathrm{Co}_{0.5} \mathrm{Fe}_{0.5} \mathrm{O}_{3}$ are limited by the oxidation thermodynamics, while that of a process using $\mathrm{La}_{0.5} \mathrm{Sr}_{0.5} \mathrm{MnO}_{3}$ is limited by the reduction thermodynamics.

The thermodynamic equilibrium for the reduction and oxidation with $\mathrm{CO}_{2}$ are given by eqn (1) and (2), respectively:

$$
\begin{gathered}
\Delta \bar{g}_{\mathrm{O}_{2}}^{\circ}(\delta, T)=-R T \ln \left(\frac{p_{\mathrm{O}_{2}}}{p^{\circ}}\right) \\
\Delta \bar{g}_{\mathrm{O}_{2}}^{\circ}(\delta, T)=\Delta G_{\mathrm{r}}^{\circ}+2 R T \ln \left(\frac{p_{\mathrm{CO}_{2}}}{p_{\mathrm{CO}}}\right)
\end{gathered}
$$

where the standard pressure, $p^{\circ}$, is 1 bar. $\Delta G_{\mathrm{r}}^{\circ}$ is the standard Gibbs free energy change of $\mathrm{CO}_{2}$ dissociation $\left(\mathrm{CO}_{2}=\mathrm{CO}+\right.$ $0.5 \mathrm{O}_{2}$ ), and $p_{\mathrm{CO}_{2}}$ and $p_{\mathrm{CO}}$ are the partial pressures of $\mathrm{CO}_{2}$ and $\mathrm{CO}$, respectively. Evidently, the reduction of a metal oxide is favorable at high temperatures and low $p_{\mathrm{O}_{2}}$, while its oxidation is favorable at low temperatures and high $p_{\mathrm{CO}_{2}}$ and low $p_{\mathrm{CO}}$. Fig. 3 quantifies this for perovskites, for which thermochemical data is typically not available from experiments. We note, while Fig. 3 gives the computed thermochemical trends at selected process conditions, the analysis can be reiterated for any set of process conditions using the raw data and scaling relations given with ESI. $\dagger$

Guiding the design of perovskites, Fig. 3 identifies materials with the most-favorable redox activity (marked in dark red) with an enthalpy change for perovskite reduction of 440-630 kJ $\mathrm{mol}_{\mathrm{O}_{2}}{ }^{-1}$ at the chosen process conditions. As expected, $\mathrm{CeO}_{2-\delta}$ with $\Delta \bar{h}_{\mathrm{O}_{2}}$ of $606 \mathrm{~kJ} \mathrm{~mol}_{\mathrm{O}_{2}}{ }^{-1}$, computed for reduction of the thermodynamically most stable mixed-terminated $\mathrm{CeO}_{2}(111)$ facet yielding stable oxygen vacancies in the subsurface of $\mathrm{CeO}_{1.75}(111){ }^{49}$ is found favorably near the top of the volcanotype plot. While the exact location of this reference depends on the oxygen nonstoichiometry, we find ceria typically exhibits well-balanced redox energetics at high-temperature redox conditions. These trends in the redox energetics indicate further increasing the reduction temperature or decreasing $p_{\mathrm{O}_{2}}$ will yield exergonic limiting free energy changes with perovskites that are characterized by slightly stronger metal-oxygen bonding.

Comparison of Fig. 3a and b shows that $\Delta \bar{g}_{\mathrm{O}_{2, \mathrm{lim}}}^{\circ}$ for the perovskites is less endergonic in a pure $\mathrm{CO}_{2}$ atmosphere, as compared to a more realistic environment of solar receiverreactors for $\mathrm{CO}_{2}$ splitting, i.e., $1 \% \mathrm{CO}$ in $\mathrm{CO}_{2} .{ }^{6}$ Analogously, we find at the selected conditions $63 \%$, that is, the majority of the 
studied perovskites are characterized by oxide oxidation-limited redox energetics ( $c f$. Fig. S17†). This confirms, as a trend, previous observations for selected perovskites, as outlined above. ${ }^{26,27,31-33}$ To validate these trends, we chose seven attractive perovskites ( $c f$. Fig. 4, marked in blue), that are located near the top of the volcano-type curve with oxide reduction at $1600 \mathrm{~K}$ and $10^{-4}$ bar $\mathrm{O}_{2}$ and oxide oxidation at $900 \mathrm{~K}$ and an atmosphere of $1 \% \mathrm{CO}$ in $\mathrm{CO}_{2}$. These conditions were chosen as realistic process conditions relevant to an industrial implementation. ${ }^{26,27,31,32}$ In particular, we chose to investigate reduction at $1600 \mathrm{~K}$, that is, below typically $1723 \mathrm{~K}$ with $\mathrm{CeO}_{2-\delta}$, ${ }^{6}$ since this would alleviate thermal and mechanical stresses in solar receiver-reactors and decrease volatilization of the redox material. For the seven chosen perovskites, Fig. 4 shows that $\mathrm{YFeO}_{3}, \mathrm{LaCo}_{0.5} \mathrm{Fe}_{0.5} \mathrm{O}_{3}, \mathrm{LaFeO}_{3}$ and $\mathrm{YMnO}_{3}$ exhibit reductionlimited energetics, while $\mathrm{LaFe}_{0.5} \mathrm{Ni}_{0.5} \mathrm{O}_{3}, \mathrm{LaCo}_{0.5} \mathrm{Ni}_{0.5} \mathrm{O}_{3}$ and $\mathrm{YCo}_{0.5} \mathrm{Fe}_{0.5} \mathrm{O}_{3}$ are exhibit oxidation-limited energetics. Compositions marked with grey symbols were considered unstable, concluded from unsuccessful synthesis attempts. For example, synthesis of $\mathrm{CeCoO}_{3}$ (with $\Delta \bar{h}_{\mathrm{O}_{2}}^{\circ}$ of about $500 \mathrm{~kJ} \mathrm{~mol}_{\mathrm{O}_{2}}{ }^{-1}$, resulting in $\Delta \bar{g}_{\mathrm{O}_{2 . \text { lim }}}^{\circ}$ of $97 \mathrm{~kJ} \mathrm{~mol}_{\mathrm{O}_{2}}{ }^{-1}$ ) was unsuccessful, as the solid synthesis product contained only $\mathrm{CeO}_{2-\delta}$ and $\mathrm{Co}_{3} \mathrm{O}_{4}(c f$. Fig. S1 $\dagger$ ), in line with previous studies. ${ }^{47,48}$

\subsection{Thermochemical stability of the perovskite phase}

Thermochemical stability is fundamental for a stable performance of a metal oxide redox material throughout multiple fuel synthesis cycles. In this work, we differentiate between the stability of the cubic perovskite phase in general and the stability against metal carbonate formation in particular. To avoid time- and resource-demanding computations of solidstate entropies, we define as a descriptor of phase stability in an inert atmosphere $r_{\text {phase }}=\sum E_{\mathrm{p} \text {,phase }} / \sum E_{\mathrm{r}, \mathrm{phase}}$, with $\sum E_{\mathrm{p} \text {,phase }}$ and $\sum E_{\mathrm{r} \text {,phase }}$ being the sums of the DFT-calculated electronic energies of the stoichiometry-dependent reaction products (possible phases in the A-B-O ternary phase diagram, such as binary metal oxides) and reactants (the perovskite and

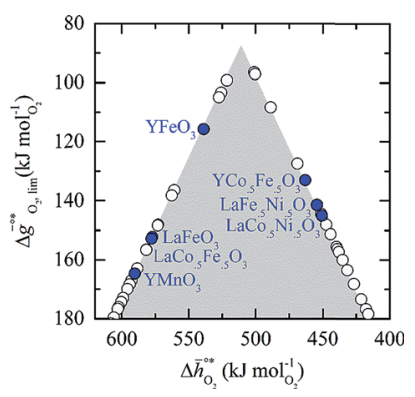

Fig. 4 A detail of Fig. 3, limiting standard partial molar Gibbs free energy for thermochemical splitting of $\mathrm{CO}_{2}\left(\Delta \bar{g}_{O_{2, \mathrm{lim}}}^{\circ}\right)$ for oxide reduction at $1600 \mathrm{~K}$ and $10^{-4}$ bar $\mathrm{O}_{2}$ and oxide oxidation at $900 \mathrm{~K}$ and in an atmosphere of $1 \% \mathrm{CO}$ in $\mathrm{CO}_{2}$ plotted vs. $\Delta \bar{h}_{\mathrm{O}_{2}}^{\circ}$. Perovskites shown with blue symbols $\left(\mathrm{YFeO}_{3}, \mathrm{LaCO}_{0.5} \mathrm{Fe}_{0.5} \mathrm{O}_{3}, \mathrm{LaFeO}_{3}, \mathrm{YMnO}_{3}, \mathrm{LaFe}_{0.5^{-}}\right.$ $\mathrm{Ni}_{0.5} \mathrm{O}_{3}, \mathrm{LaCO}_{0.5} \mathrm{Ni}_{0.5} \mathrm{O}_{3}$, and $\left.\mathrm{YCO}_{.5} \mathrm{Fe}_{0.5} \mathrm{O}_{3}\right)$ are further examined experimentally. Perovskites shown with grey symbols were considered unstable, as discussed in Section 2.2. the balance $\mathrm{O}_{2}$ ) at $0 \mathrm{~K}$. Analogously, we define as a descriptor of the thermochemical stability of a perovskite against carbonate formation in presence of $\mathrm{CO}_{2} r_{\text {carb }}=\sum E_{\mathrm{p}, \mathrm{carb}} / \sum E_{\mathrm{r}, \mathrm{carb}}$, with $\sum E_{\mathrm{p}, \mathrm{carb}}$ and $\sum E_{\mathrm{r}, \mathrm{carb}}$ being the sums of the DFT-calculated electronic energies of the stoichiometry-dependent reaction products $\left(\mathrm{ACO}_{3}\right.$ carbonates and binary metal oxides $)$ and reactants (the perovskite and $\mathrm{CO}_{2}$ ) at $0 \mathrm{~K}$. Both stability descriptors indicate stronger stability of the perovskite with lower values. Details of this analysis are given with $\operatorname{ESI} \dagger$ ( $c f$. eqn (6) and (7)).

Fig. 5 shows $r_{\text {phase }}$ for $63 \mathrm{ABO}_{3}$-type perovskites ( $c f$. Fig. 5a) and $r_{\text {carb }}$ for $36 \mathrm{ABO}_{3}$-type perovskites ( $c f$. Fig. $5 \mathrm{~b}$ ) as a function of $\Delta \bar{h}_{\mathrm{O}_{2}}^{\circ}$. Since experimental data for Y and La carbonates is very

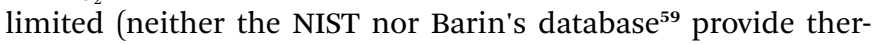
mochemical data for these compounds and their lattice constants are unknown to the best of our knowledge), we focused our analysis of carbonate formation on perovskites containing divalent alkaline earth metals $\left(\mathrm{A}=\mathrm{Mg}^{2+}, \mathrm{Ca}^{2+}, \mathrm{Sr}^{2+}\right.$ and $\left.\mathrm{Ba}^{2+}\right)$. We find perovskites with divalent $\mathrm{A}$ cations exhibit decreasing stability (Fig. $5 \mathrm{a}$ and b) with increasing $\Delta \bar{h}_{\mathrm{O}_{2}}^{\circ}$. That is, a stable perovskite phase and an unstable carbonate phase correlate both with strong metal-oxygen binding within the perovskite. The stability of perovskites containing trivalent and tetravalent A cations do not show such a clear trend (red square

a)
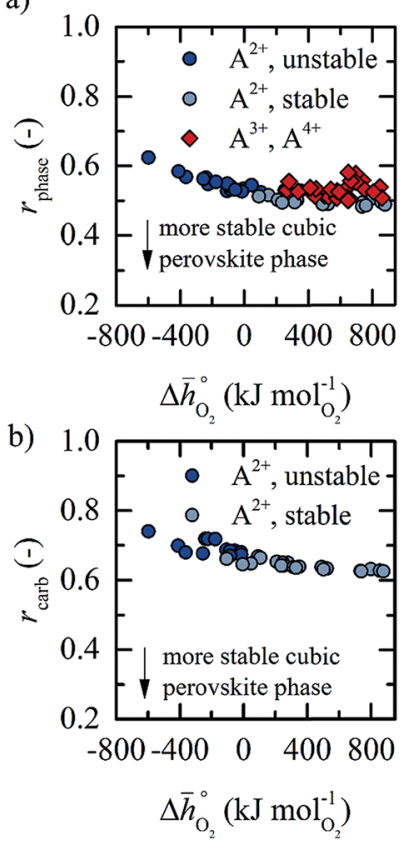

Fig. 5 Computed descriptors for the thermochemical stability of the cubic perovskite phase (a) in inert atmosphere, $r_{\text {phase }}=\sum E_{\text {p.phase }} /$ $\sum E_{r \text {,phase }}$ computed for $63 \mathrm{ABO}_{3}$-type perovskites, and (b) in $\mathrm{CO}_{2}$ atmosphere against metal carbonate formation, $r_{\text {carb }}=\sum E_{\mathrm{p}, \mathrm{carb}} /$ $\sum E_{r, \text { carb }}$ computed for $36 \mathrm{ABO}_{3}$-type perovskites, plotted vs. the standard partial molar enthalpy change $\Delta \bar{h}_{\mathrm{O}_{2}}^{\circ}$. Blue circles represent $\mathrm{ABO}_{3}$ stoichiometry with divalent $\mathrm{A}$ cations $\left(\mathrm{Mg}^{2+}, \mathrm{Ca}^{2+}, \mathrm{Sr}^{2+}\right.$, and $\left.\mathrm{Ba}^{2+}\right)$, red diamonds represent $\mathrm{ABO}_{3}$ stoichiometry with trivalent or tetravalent $\mathrm{A}$ cations $\left(\mathrm{La}^{3+}, \mathrm{Y}^{3+}\right.$, and $\left.\mathrm{Ce}^{4+}\right)$, and light blue circles represent materials with $\mathrm{ABO}_{3}$ stoichiometry and divalent $\mathrm{A}$ cations that are thermochemically stable, as indicated by their stability descriptors discussed in Section 2.2. 
symbols in Fig. 5a). Furthermore, we find both stability descriptors for perovskites with divalent $\mathrm{A}$ cations reach a plateau at $\Delta \bar{h}_{\mathrm{O}_{2}}^{\circ}$ of about $200 \mathrm{~kJ} \mathrm{~mol}_{\mathrm{O}_{2}}{ }^{-1}$. That is, we can expect that the thermochemical stability of perovskites containing $\mathrm{A}^{2+}$ cations will not further increase when the metal-oxygen bond becomes stronger than $200 \mathrm{~kJ} \mathrm{~mol}_{\mathrm{O}_{2}}{ }^{-1}$. Therefore, we consider perovskites containing divalent A cations and with $r_{\text {carb }}<0.66$ and $r_{\text {phase }}<0.51$ as thermochemically stable ( $c f$. light blue circles round symbols in Fig. $5 \mathrm{a}$ and b). We note this selfconsistent analysis is limited to the cubic perovskite phase. Other descriptors, such as the Goldschmidt tolerance factor, can be employed to further investigate perovskite stability.

In Section 2.1 we describe superior redox energetics for perovskites with $\Delta \bar{h}_{\mathrm{O}_{2}}^{\circ}$ in the range of $440-630 \mathrm{~kJ} \mathrm{~mol}_{\mathrm{O}_{2}}{ }^{-1}$ (cf. Fig. 3). This range describes materials with metal-oxygen bonding stronger than $200 \mathrm{~kJ} \mathrm{~mol}_{\mathrm{O}_{2}}{ }^{-1}$, indicating that all analyzed perovskites that contain $\mathrm{A}^{2+}$ cations and that show attractive redox energetics are thermochemically stable at the chosen process conditions. This is assuming that the $\mathrm{AA}^{\prime} \mathrm{BO}_{3}{ }^{-}$, $\mathrm{ABB}^{\prime} \mathrm{O}_{3}$ - and $\mathrm{AA}^{\prime} \mathrm{BB}^{\prime} \mathrm{O}_{3}$-type compositions follow the correlation established here for $\mathrm{ABO}_{3}$-type compositions.

\subsection{Choosing a reasonable set of redox conditions}

Choosing a reasonable set of process conditions is fundamental for consistent materials screening yielding results that are comparable to experiments with metal oxides tested at their specific set of favorable process conditions, as outlined in Section 2.1. For instance, given the often poor perovskite oxidation energetics, we find exergonic $\Delta \bar{g}_{\mathrm{O}_{2 . \text { lim }}}^{\circ}$ for reduction at $1600 \mathrm{~K}$ and $10^{-5}$ bar $\mathrm{O}_{2}$ and oxidation at $900 \mathrm{~K}$ with a molar ratio of $\mathrm{CO}_{2}$ feed to oxygen vacancies present in the solid of 10000 . At these conditions, $\mathrm{LaNiO}_{3}, \mathrm{CeNiO}_{3}$, and $\mathrm{YCoO}_{3}$ reach $\Delta \bar{g}_{\mathrm{O}_{2, \text { lim }}}^{\circ}$ desirably negative values of $-6.40,-5.62$ and $-1.78 \mathrm{~kJ} \mathrm{~mol}_{\mathrm{O}_{2}}{ }_{-1}$, respectively. However, these process conditions are unfavorable and would lead to a significant drop of the overall solar-to-fuel energy conversion efficiency of the redox cycle. Both, the low concentrations of $\mathrm{O}_{2}$ during the reduction and the excess of oxidant imply additional energy penalties for gas separations and heat exchange, increasing the net-energy penalties. ${ }^{49}$ Analogously, for realization of isothermal $\mathrm{CO}_{2}$ splitting with perovskites we find exergonic redox energetics at $T_{\text {red }}=T_{\text {ox }}=$ $1600 \mathrm{~K}$, a molar $\mathrm{CO}_{2}$ to oxygen vacancy ratio of 1000 , and $10^{-7}$ bar $\mathrm{O}_{2}$. This agrees well with the analysis by Meredig et al. ${ }^{\mathbf{4 4}}$ who showed that large temperature differences between oxidation and reduction are required for thermodynamically favorable redox cycles. The authors further demonstrated that this advantage of relatively large temperature swings is materialindependent and driven solely by the temperature difference and the entropy of the $\mathrm{O}_{2} \cdot{ }^{44}$ The product of these two driving forces must be equal or larger than twice the free energy of formation of $\mathrm{H}_{2} \mathrm{O}$ or $\mathrm{CO}_{2}$, which is the barrier to a thermodynamically favorable two-step redox cycle. ${ }^{\mathbf{4 4}}$

In summary, perovskites do not outperform state-of-the-art nonstoichiometric ceria for solar thermochemical fuel production at the high-temperature process conditions which are required to render ceria redox-active. However, perovskites offer the possibility to decrease the maximum temperature of a redox cycle, which may alleviate thermal and mechanical stress in solar receiver-reactors and may diminish volatilization of solids. Realization of such redox cycles at lower temperatures with perovskite redox materials comes, however, at the costs of additional energy penalties for providing low $\mathrm{O}_{2}$ partial pressures during oxide reduction and/or excess oxidant during oxide oxidation. An energy balance and calculation of the theoretical solar-to-fuel energy conversion efficiency assuming thermodynamic equilibrium is found in Takacs et al. ${ }^{32}$

\section{Experimental validation}

\subsection{Oxygen nonstoichiometry measurements}

To assess the trends of the redox energetics established above via DFT, we evaluated the redox activity of selected perovskites (i.e., $\mathrm{YFeO}_{3}, \mathrm{LaCo}_{0.5} \mathrm{Fe}_{0.5} \mathrm{O}_{3}, \mathrm{LaFeO}_{3}, \mathrm{YMnO}_{3}, \mathrm{LaFe}_{0.5} \mathrm{Ni}_{0.5} \mathrm{O}_{3}$, $\mathrm{LaCo}_{0.5} \mathrm{Ni}_{0.5} \mathrm{O}_{3}$ and $\mathrm{YCo}_{0.5} \mathrm{Fe}_{0.5} \mathrm{O}_{3}$, as marked with blue symbols in Fig. 4) by continuous redox cycling with a thermogravimetric analyzer (TGA). As all investigated perovskites are nonstoichiometric, Fig. S5† provides a detailed analysis of the oxygen nonstoichiometry, while we identify the discussed materials within the manuscript for simplicity with their stoichiometric compositions. In these studies perovskite reduction was at $1573 \mathrm{~K}$ and 1 bar of $10^{-4}, 3.04 \times 10^{-4}$, and $5.07 \times 10^{-4}$ bar $\mathrm{O}_{2}$ in Ar, respectively, and perovskite oxidation was at 873 , 1073 , and $1273 \mathrm{~K}$ and 1 bar of $1 \% \mathrm{CO}$ in $\mathrm{CO}_{2}$. To facilitate comparison with experiments that use $\mathrm{O}_{2}$ as oxidant, we note these oxidation conditions correspond to $\mathrm{O}_{2}$ partial pressures of $1.88 \times 10^{-21}, 3.79 \times 10^{-15}$, and $7.75 \times 10^{-11}$ bar $\mathrm{O}_{2}$, respectively, determined from the relation between the activities of $\mathrm{CO}_{2}, \mathrm{CO}$, and $\mathrm{O}_{2} \cdot{ }^{50}$ The results of the TGA measurements are shown with Fig. S2 and S3 $\uparrow$ and are utilized here to calculate the oxygen nonstoichiometries with:

$$
\delta=\Delta m_{\mathrm{s}} \frac{M_{\mathrm{s}}}{M_{\mathrm{O}}}
$$

where $\Delta m_{\mathrm{s}}$ is the relative weight change (in $\mathrm{g} / \mathrm{g}$ ), and $M_{\mathrm{s}}$ and $M_{\mathrm{O}}$ are the molar mass of the sample and of monoatomic oxygen, respectively (in $\mathrm{g} \mathrm{mol}^{-1}$ ). The oxygen exchange capacity is then defined as $\Delta \delta=\delta_{\text {red }}-\delta_{\text {ox }}$ (in mol O per mol $\mathrm{ABO}_{3}$ ).

To assess the thermodynamics of the oxygen exchange, Fig. 6 shows the oxygen exchange capacity for reduction at $1573 \mathrm{~K}$ in $10^{-4}$ bar $\mathrm{O}_{2}$ and oxidation at $873 \mathrm{~K}$ in $1 \% \mathrm{CO}$ in $\mathrm{CO}_{2}$ (equivalent to $1.88 \times 10^{-21}$ bar $\mathrm{O}_{2}$ ), respectively. For comparison, $\Delta \delta$ of $\mathrm{CeO}_{2-\delta}$, marked with a grey line, was calculated from Panlener

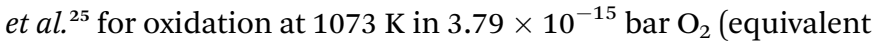
to $1 \% \mathrm{CO}$ in $\mathrm{CO}_{2}$ ) and reduction at $1773 \mathrm{~K}$ in $10^{-4}$ bar $\mathrm{O}_{2}$, which are typical conditions for thermochemical splitting of $\mathrm{CO}_{2}$ with $\mathrm{CeO}_{2-\delta}$. The analysis shows that all perovskites, except $\mathrm{YCo}_{0.5^{-}}$ $\mathrm{Fe}_{0.5} \mathrm{O}_{3}$, have a smaller $\Delta \delta$ than $\mathrm{CeO}_{2-\delta}$ (found here with $\Delta \delta=$ 0.07 , which is comparable to the values reported by previous experimental investigations of ceria $^{25}$ ). Furthermore, after perovskite oxidation, $\mathrm{YCo}_{0.5} \mathrm{Fe}_{0.5} \mathrm{O}_{3}$ does not fully reoxidize using 0.2 bar $\mathrm{O}_{2}$, ( $c f$. Fig. $\mathrm{S} 3$ and $\left.\mathrm{S} 6 \dagger\right)$, which will result in smaller $\Delta \delta$ established in consecutive redox cycles. $\mathrm{LaCo}_{0.5^{-}}$ $\mathrm{Fe}_{0.5} \mathrm{O}_{3}, \quad \mathrm{LaFe}_{0.5} \mathrm{Ni}_{0.5} \mathrm{O}_{3}$, and $\mathrm{LaCo}_{0.5} \mathrm{Ni}_{0.5} \mathrm{O}_{3}$ show nominally 


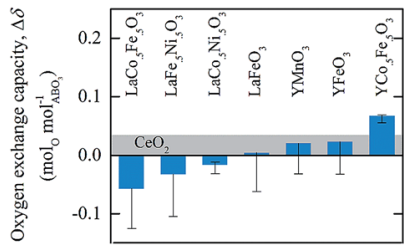

Fig. 6 Experimentally measured oxygen exchange capacity, $\Delta \delta$, of $\mathrm{LaCO}_{0.5} \mathrm{Fe}_{0.5} \mathrm{O}_{3}, \quad \mathrm{LaFe}_{0.5} \mathrm{Ni}_{0.5} \mathrm{O}_{3}, \quad \mathrm{LaCO}_{0.5} \mathrm{Ni}_{0.5} \mathrm{O}_{3}, \quad \mathrm{LaFeO}_{3}, \quad \mathrm{YMnO}_{3}$, $\mathrm{YFeO}_{3}$, and $\mathrm{YCO}_{5} \mathrm{Fe}_{0.5} \mathrm{O}_{3}$ for oxide oxidation at $873 \mathrm{~K}$ in $1 \% \mathrm{CO}$ in $\mathrm{CO}_{2}$ $\left(p_{\mathrm{O}_{2}}=1.88 \times 10^{-21}\right.$ bar) and oxide reduction at $1573 \mathrm{~K}$ in $10^{-4}$ bar $\mathrm{O}_{2}$. As a reference, the grey area marks $\Delta \delta$ for $\mathrm{CeO}_{2-\delta}$, as calculated from Panlener et al..$^{25}$ for oxidation at $1073 \mathrm{~K}$ in $3.79 \times 10^{-15}$ bar $\mathrm{O}_{2}$ (corresponding to $1 \% \mathrm{CO}$ in $\mathrm{CO}_{2}$ ) and reduction at $1773 \mathrm{~K}$ in $10^{-4}$ bar $\mathrm{O}_{2}$ (which are typical redox cycle conditions for ceria). Error bars are calculated as the sum of the experimental uncertainties for the oxidation and reduction runs, arising from minor mass changes of the samples at a stabilization temperature of $873 \mathrm{~K}$ and drift corrections.

negative $\Delta \delta$, owing to their strong loss of $\mathrm{O}_{2}$ (that is, perovskite reduction) at oxidation conditions. The relatively large errors originate from drift corrections in the reduction and oxidation runs, from which the oxygen exchange capacities were calculated.

To demonstrate how crucial the choice of a reasonable set of redox conditions is, we oxidized $\mathrm{YCo}_{0.5} \mathrm{Fe}_{0.5} \mathrm{O}_{3}, \mathrm{LaCo}_{0.5} \mathrm{Ni}_{0.5} \mathrm{O}_{3}$, and $\mathrm{LaFe}_{0.5} \mathrm{Ni}_{0.5} \mathrm{O}_{3}$ at $873 \mathrm{~K}$ with $100 \% \mathrm{CO}_{2}$, which corresponds to a $p_{\mathrm{O}_{2}}\left(3.67 \times 10^{-9}\right.$ bar $\left.\mathrm{O}_{2}\right)$ that is by several orders of magnitude higher than that of $1 \% \mathrm{CO}$ in $\mathrm{CO}_{2}$ at the same temperature $\left(1.88 \times 10^{-21}\right.$ bar $\left.\mathrm{O}_{2}\right)$. To assess the sensitivity of the perovskites to these oxidation conditions, Fig. 7 shows the oxygen nonstoichiometry for perovskite oxidation, $\delta_{\text {ox }}$, measured in $1 \% \mathrm{CO}$ in $\mathrm{CO}_{2}$ and plotted as a function of that measured in $100 \% \mathrm{CO}_{2}$. Parity indicates materials that are insensitive to this difference in the oxidation potential of the gas composition. At all investigated temperatures, all investigated perovskites are located above parity, indicating a high sensitivity to the oxidation potential of the gas composition. This observation agrees well with the DFT-derived trends discussed above with Fig. 3. As a trend, we find perovskites with poor oxidation energetics are most sensitive to the presence of $\mathrm{CO}$ in the $\mathrm{CO}_{2}$ oxidant. That is, $\mathrm{YCo}_{0.5} \mathrm{Fe}_{0.5} \mathrm{O}_{3}, \mathrm{LaCo}_{0.5} \mathrm{Ni}_{0.5} \mathrm{O}_{3}$, and $\mathrm{LaFe}_{0.5} \mathrm{Ni}_{0.5} \mathrm{O}_{3}$ are (comparing the set of three perovskites) least, intermediately, and most sensitive to the presence of $\mathrm{CO}$ in $\mathrm{CO}_{2}$ ( $c f$. Fig. 7), and show positive, negative, and most negative $\Delta \delta$ ( $c f$. Fig. 6), which correlates well with the average electronegativity of the metals at their B-type interstitials, that is $1.86,1.87$, and 1.90, respectively. Analogously, $\mathrm{CeO}_{2-\delta}$, with Ce having a much lower electronegativity of 1.12, exhibits redox energetics that are essentially insensitive to the presence of CO. ${ }^{6,25}$ For example, oxidation of $\mathrm{CeO}_{2-\delta}$ at $873 \mathrm{~K}$ in $100 \% \mathrm{CO}_{2}$ and $1 \% \mathrm{CO}$ in $\mathrm{CO}_{2}$ is reported with $\delta_{\mathrm{ox}}=0.0001$ and $\delta_{\mathrm{ox}}=0.0006$ $\mathrm{mol}_{\mathrm{O}} \mathrm{mol}_{\mathrm{CeO}_{2}}{ }^{-1}$, respectively. ${ }^{25}$ Compared to this difference in $\delta_{\text {ox }}$ within the same order of magnitude for $\mathrm{CeO}_{2-\delta}$, we find an increase of $\delta_{\text {ox }}$ for $\mathrm{YCo}_{0.5} \mathrm{Fe}_{0.5} \mathrm{O}_{3}, \mathrm{LaCo}_{0.5} \mathrm{Ni}_{0.5} \mathrm{O}_{3}$, and $\mathrm{LaFe}_{0.5^{-}}$ $\mathrm{Ni}_{0.5} \mathrm{O}_{3}$ from $-0.011,0.004$, and $0.003 \mathrm{~mol}_{\mathrm{O}} \mathrm{mol}_{\mathrm{ABO}_{3}}{ }^{-1}$ to 0.066 , 0.190 , and $0.392 \mathrm{~mol}_{\mathrm{O}} \mathrm{mol}_{\mathrm{ABO}_{3}}{ }^{-1}$ (for $873 \mathrm{~K}$ and $100 \% \mathrm{CO}_{2}$ vs.
$1 \% \mathrm{CO}$ in $\mathrm{CO}_{2}$ ), respectively. That is a difference in $\delta_{\text {ox }}$ by two to three orders of magnitude.

This inferior oxidation performance of the perovskites in the presence of $\mathrm{CO}$ in the $\mathrm{CO}_{2}$ oxidant is a major downside, since the $\mathrm{CO}$ product is present in a solar receiver-reactor throughout the entire oxidation period at conditions relevant for industrial implementation. ${ }^{6}$ Alternatively, the oxidation performance of perovskites can be augmented by flooding the reactor with inert gas and/or excess $\mathrm{CO}_{2}$ to decrease $\mathrm{CO}$ concentrations, but this may be energetically costly, as it introduces additional energy penalties for gas separation and heat exchange.

\subsection{Fine-tuning the oxygen exchange capacity}

To evaluate the possibility to fine-tune the oxygen exchange capacity of perovskites, the following discusses the trends in the redox energetics with varying metal cation concentrations. The discussion above focused on perovskite compositions with $\mathrm{A}: \mathrm{A}^{\prime}$ and $\mathrm{B}: \mathrm{B}^{\prime}$ cation ratios equal to unity. To estimate trends in the oxygen exchange capacity of perovskites with metal cation ratios that differ from unity, Fig. 8a shows the volcano-type curve for three selected materials: $\mathrm{YFeO}_{3}, \mathrm{YCo}_{0.5} \mathrm{Fe}_{0.5} \mathrm{O}_{3}$, and $\mathrm{YCoO}_{3}$. The plot indicates oxidation-limited redox thermodynamics for $\mathrm{YCo}_{0.5} \mathrm{Fe}_{0.5} \mathrm{O}_{3}$ and $\mathrm{YCoO}_{3}$ (since both materials are located on the right side of the volcano) and reduction-limited redox thermodynamics for $\mathrm{YFeO}_{3}$ (located on the left side of the volcano). Thus, we hypothesize increasing the concentration of the Fe dopant in $\mathrm{YCo}_{0.5} \mathrm{Fe}_{0.5} \mathrm{O}_{3}$ stabilizes metal-oxygen bonds and, in turn, yields compositions located closer to the top of the volcano.

To evaluate this hypothesis, we performed TGA experiments for $\mathrm{YFeO}_{3}, \mathrm{YCo}_{0.1} \mathrm{Fe}_{0.9} \mathrm{O}_{3}, \mathrm{YCo}_{0.3} \mathrm{Fe}_{0.7} \mathrm{O}_{3}$, and $\mathrm{YCo}_{0.5} \mathrm{Fe}_{0.5} \mathrm{O}_{3}$ with reduction at $1573 \mathrm{~K}$ in $10^{-4}$ bar $\mathrm{O}_{2}$ and oxidation at $873 \mathrm{~K}$ in $1 \%$ $\mathrm{CO}$ in $\mathrm{CO}_{2}\left(1.88 \times 10^{-21}\right.$ bar $\left.\mathrm{O}_{2}\right)$. Fig. $8 \mathrm{~b}$ shows the oxygen exchange capacities obtained for these materials. We find increasing the $\mathrm{Fe}$ concentration in $\mathrm{YCo}_{0.5} \mathrm{Fe}_{0.5} \mathrm{O}_{3}$ increases its oxygen exchange capacity from $0.07 \mathrm{~mol}_{\mathrm{O}} \mathrm{mol}_{\mathrm{ABO}_{3}}{ }^{-1}$ for $\mathrm{YCo}_{0.5^{-}}$ $\mathrm{Fe}_{0.5} \mathrm{O}_{3}$ to $0.11 \mathrm{~mol}_{\mathrm{O}} \mathrm{mol}_{\mathrm{ABO}_{3}}{ }^{-1}$ for $\mathrm{YCo}_{0.3} \mathrm{Fe}_{0.7} \mathrm{O}_{3}$, which confirms our hypothesis. Further increasing the Fe concentration of $\mathrm{YCo}_{0.3} \mathrm{Fe}_{0.7} \mathrm{O}_{3}$ decrease $\Delta \delta$, which we suggest indicates increasing energetic limitations arising from the unfavorable thermodynamic equilibrium of the perovskite reduction, analogous to that of $\mathrm{YFeO}_{3}$ ( $c f$. Fig. 8a). This trend in the bonding strength of the lattice oxygen in metal-doped bulk perovskites is

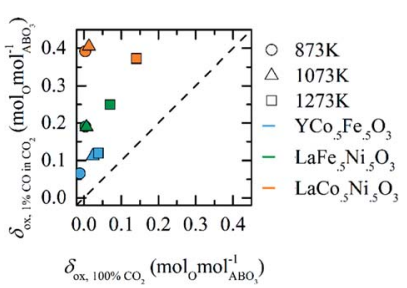

Fig. 7 Oxygen nonstoichiometry for perovskite oxidation, $\delta_{\mathrm{Ox}}$,

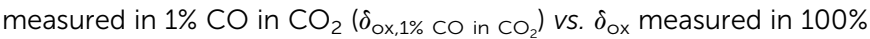

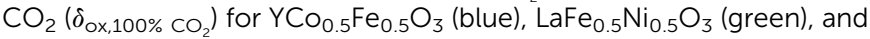
$\mathrm{LaCO}_{0.5} \mathrm{Ni}_{0.5} \mathrm{O}_{3}$ (orange), and measured at $873 \mathrm{~K}$ (circles), $1073 \mathrm{~K}$ (triangles), and $1273 \mathrm{~K}$ (squares). The dashed line marks parity. 
a)
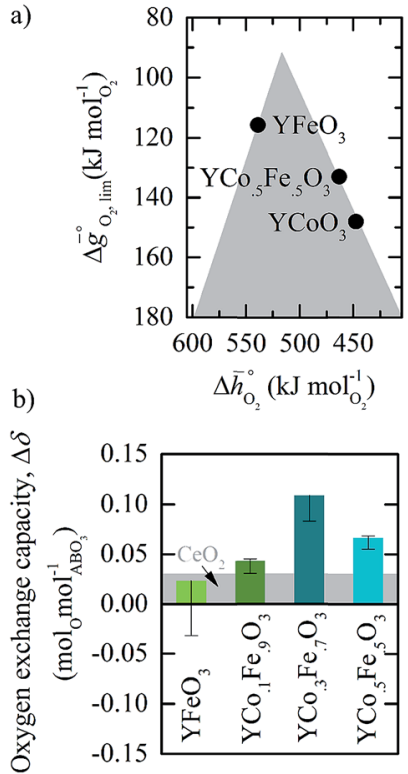

Fig. 8 (a) Volcano-type curve for $\mathrm{YFeO}_{3}, \mathrm{YCO}_{0.5} \mathrm{Fe}_{0.5} \mathrm{O}_{3}$, and $\mathrm{YCoO}_{3}$. (b) Oxygen exchange capacity, $\Delta \delta$, for $\mathrm{YFeO}_{3}, \mathrm{YCO}_{0.1} \mathrm{Fe}_{0.9} \mathrm{O}_{3}, \mathrm{YCO}_{0.3}-$ $\mathrm{Fe}_{0.7} \mathrm{O}_{3}$, and $\mathrm{YCO}_{0.5} \mathrm{Fe}_{0.5} \mathrm{O}_{3}$ for oxide oxidation at $873 \mathrm{~K}$ in $1 \% \mathrm{CO}$ in $\mathrm{CO}_{2}$ at $873 \mathrm{~K}\left(p_{\mathrm{O}_{2}}=1.88 \times 10^{-21}\right.$ bar $)$ and oxide reduction at $1573 \mathrm{~K} \mathrm{in}$ $10^{-4}$ bar $\mathrm{O}_{2}$. As a reference, the grey area marks $\Delta \delta$ for $\mathrm{CeO}_{2-\delta}$ (equivalent to that shown with Fig. 6). Error bars are the sum of the experimental uncertainties for the oxidation and reduction runs.

analogous to the trend in the adsorption energy of molecular fragments at bimetallic surfaces, ${ }^{51}$ which describes the similarity between the bonding of the gaseous reactant with varying coordination at the surface $v s$. in the bulk. Generally, these results demonstrate the utility of the presented electronic structure calculations to guide the rational design of perovskites. The presented methodology facilitates screening for redox-active materials at selected process conditions and finetuning of the oxygen exchange capacity for this highly versatile class of metal oxides for solar-driven thermochemical fuel synthesis.

\subsection{Crystal phase stability and carbonate formation}

This section validates the DFT-predicted trend that stronger endothermic perovskite reduction, that is, more positive $\Delta \bar{h}_{\mathrm{O}_{2}}$ values, indicates increasing thermochemical stability of the perovskite against a phase change yielding binary metal oxides and against carbonate formation. These electronic structure calculations are discussed in detail in Section 2.2, with trends in the metal carbonate formation predicted only for perovskites with $\mathrm{ABO}_{3}$ stoichiometry. To this end, we evaluated the stability of selected perovskites using TGA, room-temperature X-ray diffraction (RT-XRD), high-temperature X-ray diffraction (HTXRD), and transmission electron microscopy (TEM). The following discusses results that are representative for the investigated materials. The complete data is provided with ESI, including Fig. S9 and S10 $\dagger$ showing HT-XRD spectra for $\mathrm{SrTiO}_{3}$, $\mathrm{SrCoO}_{3}, \mathrm{SrMnO}_{3}, \mathrm{LaAlO}_{3}, \mathrm{BaCoO}_{3}$ and $\mathrm{BaMnO}_{3}$ at 310, 675, 875, 1075 , and $1275 \mathrm{~K}$, in $100 \% \mathrm{CO}_{2}$ (to assess carbonate formation) and in 0.2 bar $\mathrm{O}_{2}$ (to assess the stability of the cubic perovskite phase), respectively.

Regarding the thermochemical stability against decomposition of the cubic perovskite phase, the HT-XRD spectra, given with Fig. S9 and $\mathrm{S} 10, \uparrow$ show segregation of $\mathrm{SrCoO}_{3}$ into lowersymmetry metal oxides. As expected, $\mathrm{SrTiO}_{3}$ remains stable, independent of temperature and pressure. This confirms the DFT-predicted stability trend, given that the lattice oxygen binds significantly stronger in $\mathrm{SrTiO}_{3}$ (with $\Delta \bar{h}_{\mathrm{O}_{2}}^{\circ}$ of about $760 \mathrm{~kJ}$ $\left.\operatorname{mol}_{\mathrm{O}_{2}}{ }^{-1}\right)$ than in $\mathrm{SrCoO}_{3}\left(\Delta \bar{h}_{\mathrm{O}_{2}}^{\circ}\right.$ of $\left.151 \mathrm{~kJ} \mathrm{~mol}_{\mathrm{O}_{2}}{ }^{-1}\right)$. Similarly, $\mathrm{SrMnO}_{3}\left(\Delta \bar{h}_{\mathrm{O}_{2}}^{\circ}\right.$ of $\left.314 \mathrm{~kJ} \mathrm{~mol}_{\mathrm{O}_{2}}{ }^{-1}\right)$ and $\mathrm{LaAlO}_{3}\left(\Delta \bar{h}_{\mathrm{O}_{2}}\right.$ of $860 \mathrm{~kJ}$ $\mathrm{mol}_{\mathrm{O}_{2}}{ }^{-1}$ ) are thermochemically stable, as they do not show phase changes upon heating in either 0.2 bar $\mathrm{O}_{2}$ or $\mathrm{CO}_{2}$, opposed to less stable $\mathrm{BaCoO}_{3}\left(\Delta \bar{h}_{\mathrm{O}_{2}}^{\circ}\right.$ of $\left.92 \mathrm{~kJ} \mathrm{~mol}_{\mathrm{O}_{2}}{ }^{-1}\right)$ and $\mathrm{BaMnO}_{3}\left(\Delta \bar{h}_{\mathrm{O}_{2}}^{\circ}\right.$ of $\left.237 \mathrm{~kJ} \mathrm{~mol}_{\mathrm{O}_{2}}{ }^{-1}\right)$. The enthalpy change of $\mathrm{BaMnO}_{3}$ reduction is near $200 \mathrm{~kJ} \mathrm{~mol}_{\mathrm{O}_{2}}{ }^{-1}$, which prohibits conclusive interpretation ( $c f$. Section 2.2 ) within an uncertainty of this guide in the order of $10 \mathrm{~kJ} \mathrm{~mol}_{\mathrm{O}_{2}}{ }^{-1}$, partly due to the approximate nature of the perovskite models (that may converge to the actual extend and distribution of oxygen nonstoichiometries at infinitely large size) and structural differences between the synthesized perovskites (such as those in crystal phase or surface morphology).

Regarding the thermochemical stability against metal carbonate formation, Fig. 9a shows the mass gain for $\mathrm{BaCoO}_{3}$, $\mathrm{SrCoO}_{3}, \mathrm{BaMnO}_{3}, \mathrm{SrMnO}_{3}$ and $\mathrm{SrTiO}_{3}$ exposed in a TGA to pure $\mathrm{CO}_{2}$ at 973,873 , and $773 \mathrm{~K}(c f$. Fig. $\mathrm{S} 9 \dagger)$. We assume this mass gain is solely due to carbonate formation, which is discussed critically further below. As a general trend, we find the extent of apparent carbonate formation increases with less endothermic $\Delta \bar{h}_{\mathrm{O}_{2}}$, as predicted. This can be seen in Fig. 9a, for instance by the relative weight changes for $\operatorname{SrCoO}_{3}\left(\Delta \bar{h}_{\mathrm{O}_{2}}\right.$ of $151 \mathrm{~kJ}$
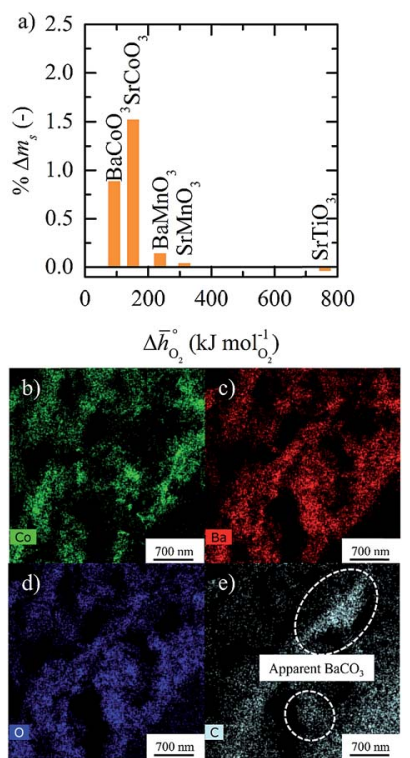

Fig. 9 (a) Percent mass change as a function of $\Delta \bar{h}_{\mathrm{O}_{2}}^{\circ}$ for $\mathrm{BaCoO}_{3}$, $\mathrm{SrCoO}_{3}, \mathrm{BaMnO}_{3}, \mathrm{SrMnO}_{3}$, and $\mathrm{SrTiO}_{3} .(\mathrm{b}-\mathrm{e})$ Drift-corrected elemental maps and their overlays for $\mathrm{BaCoO}_{3}$ obtained by TEM analysis. 
$\left.\operatorname{mol}_{\mathrm{O}_{2}}{ }^{-1}\right), \mathrm{BaMnO}_{3}\left(\Delta \bar{h}_{\mathrm{O}_{2}}^{\circ}\right.$ of $\left.237 \mathrm{~kJ} \mathrm{~mol}_{\mathrm{O}_{2}}{ }^{-1}\right)$ and $\mathrm{SrTiO}_{3}\left(\Delta \bar{h}_{\mathrm{O}_{2}}^{\circ}\right.$ of $760 \mathrm{~kJ} \mathrm{~mol}_{\mathrm{O}_{2}}{ }^{-1}$ ) of $+1.5,+0.15$ and $-0.047 \mathrm{wt} \%$, respectively. $\mathrm{SrCoO}_{3}$ and $\mathrm{BaCoO}_{3}$ deviate from this trend, which may reflect differences in the crystal phase between the prepared samples (hexagonal $\mathrm{BaCoO}_{3}$ vs. cubic $\mathrm{SrCoO}_{3}$, both shown with Fig. S12 $\dagger$ ) and the models (cubic perovskites), as well as differences in the oxygen nonstoichiometries between the prepared samples (possibly with $\delta>0$, as we reported previously for simpler compositions, such as $\mathrm{BaCoO}_{2.58}$ and $\left.\mathrm{SrCoO}_{2.95}\right)^{\mathbf{4 6}}$ and the models (which assume at oxidizing conditions $\delta=0$ ).

To obtain evidence for the assumption that the weight gain recorded in presence of $\mathrm{CO}_{2}$ is indeed due to metal carbonate formation, we analyzed selected samples using RT-XRD. This data is shown with Fig. S12, $\dagger$ which confirms formation of $\mathrm{SrCO}_{3}$ by $\mathrm{SrCoO}_{3}$ and of $\mathrm{BaCO}_{3}$ by $\mathrm{BaCoO}_{3}$. This is expected, in particular for these two perovskites that show the highest weight gains in the oxidation runs ( $c f$. Fig. 9). To visualize and locate metal carbonate formation at the perovskite surface, TEM measurements are given with Fig. S13-S16. $\dagger$ As it can be concluded from the spatial distribution of the signals for carbon, oxygen, and the A-site metals, the analysis indicates formation of metal carbonates by $\mathrm{SrCoO}_{3}$ and $\mathrm{BaCoO}_{3}$, more so than by $\mathrm{SrTiO}_{3}$ and $\mathrm{SrMnO}_{3}$. This is shown with Fig. 9b-e, showing as an example the TEM data for $\mathrm{BaCoO}_{3}$. We conclude apparent formation of $\mathrm{BaCO}_{3}$ in surface regions with signals for $\mathrm{Ba}, \mathrm{C}$ and $\mathrm{O}$, but not for Co (as indicated in Fig. 9e). Equivalent regions we find for $\mathrm{SrCoO}_{3}$ ( $c f$. Fig. $\mathrm{S} 15 \dagger$ ), but neither for $\mathrm{SrTiO}_{3}$ (cf. Fig. $\mathrm{S} 14 \dagger)$ nor for $\mathrm{SrMnO}_{3}$ ( $c f$. Fig. S16 $\dagger$ ), which is in agreement with the trend in the weight changes discussed above ( $c f$. Fig. 9a).

\section{Conclusions}

We used density functional theory to screen a large range of perovskites for their redox activity and thermochemical stability for solar-driven thermochemical splitting of $\mathrm{CO}_{2}$. The computationally predicted trends are validated experimentally and employed for the fine-tuning of the oxygen exchange capacity of selected perovskite compositions. Our major findings are, firstly, perovskites with thermodynamically favorable redox energetics at reasonable process conditions can be identified with an enthalpy of metal oxide reduction at ambient conditions in the range of 440 to $630 \mathrm{~kJ} \mathrm{~mol}_{\mathrm{O}_{2}}{ }^{-1}$. Secondly, $\mathrm{ABO}_{3}$-type perovskites containing divalent metal cations at the A-site exhibit a stable cubic crystal phase in an inert atmosphere and thermochemical stability against metal carbonate formation in presence of $\mathrm{CO}_{2}$, provided their enthalpy of metal oxide reduction is equal to or larger than $200 \mathrm{~kJ} \mathrm{~mol}_{\mathrm{O}_{2}}{ }^{-1}$. This descriptor-based guide for the rational design of perovskites is useful for predicting redox-activity of a perovskite at a selected set of process conditions, fine-tuning of the oxygen exchange capacity via metal cation doping, and for assessing the thermochemical stability of the perovskite phase in an inert or $\mathrm{CO}_{2}$ atmosphere. These properties of this class of highly versatile metal oxides is particularly important for designing redox materials for thermochemical fuel synthesis, but as well central to related high-temperature applications, such as carbonatefree solid oxide fuel cells.

Furthermore, we demonstrated the importance of choosing an appropriate set of redox cycle conditions for the screening of perovskite redox materials, as this class of materials with typically oxidation-limited redox energetics exhibits a significantly higher sensitivity to the composition of the oxidant, very different to the reduction-limited redox energetics of nonstoichiometric ceria. In this regard, we conclude perovskites do not outperform nonstoichiometric ceria for solar-driven thermochemical fuel synthesis applications at the high-temperature swing conditions used most beneficially with ceria. However, certain perovskites are found redox-active at lower oxide reduction temperatures, offering an option to alleviate thermal and mechanical stress in solar receiver-reactors and to diminish volatilization of solids. This, however, comes at the costs of additional energy penalties for providing low $\mathrm{O}_{2}$ partial pressures and/or excess oxidant.

\section{Experimental section}

\subsection{Electronic structure calculations}

All DFT calculations were performed using the Grid-based projector-augmented wave (GPAW) code. ${ }^{52,53}$ Atomic configurations were handled in the atomic simulation environment (ASE) ${ }^{54}$ with exchange-correlation interactions treated by the revised Perdew-Burke-Ernzerhof (RPBE) functional. ${ }^{55}$ The atomic geometries were optimized employing the line search Broyden-Fletcher-Goldfarb-Shanno (BFGS) algorithm until the maximum force was less than $0.05 \mathrm{eV}^{-1}$. Convergence was achieved using a Fermi-Dirac smearing of $0.1 \mathrm{eV}$. The results were extrapolated to $0 \mathrm{~K}$. Analogous to previous studies, ${ }^{33,42,46,56-58}$ all DFT calculations reported here use the generalized gradient approximation (GGA) without a Hubbard $U$ correction, as previous studies demonstrated that this does not improve the description of surface activity with the employed perovskite models. ${ }^{42} \mathrm{AA}^{\prime} \mathrm{BB}^{\prime} \mathrm{O}_{3}$ perovskites were modeled with $\mathrm{A}_{2} \mathrm{~B}_{2} \mathrm{O}_{6}$ models containing two cubic $\mathrm{ABO}_{3}$ unit cells with the same or two different metals ( $\mathrm{Mg}, \mathrm{Ca}, \mathrm{Sr}, \mathrm{Ba}, \mathrm{Y}, \mathrm{La}$ or $\mathrm{Ce}$ ) at the twelve-fold coordinated A-site interstices, and the same or two different metals (Ti, Cr, Mn, Fe, Co, Ni, Cu, $\mathrm{Zr}$ or Al) at the sixfold coordinated B-site interstices. All atoms of the bulk models were allowed to optimize their positions (relax). In total, 297 compositions were modeled, with either $\mathrm{ABO}_{3}-(63$ compositions), $\mathrm{AA}^{\prime} \mathrm{BO}_{3}-$ (77 compositions), $\mathrm{ABB}^{\prime} \mathrm{O}_{3^{-}}$(67 compositions), or $\mathrm{AA}^{\prime} \mathrm{BB}^{\prime} \mathrm{O}_{3}$-type stoichiometry (90 compositions). The Brillouin zone of the bulk models with periodic boundary conditions in all directions was sampled with $4 \times 4 \times 4 k$-points. Compositions containing $\mathrm{Mn}$, Fe, Co, or Ni were modeled using spinpolarized calculations. The DFT-computed lattice constants are found within 0.07 to $2.17 \%$ of the experimental values. The minimum and maximum values of the computed lattice constants of the $\mathrm{ABO}_{3}, \mathrm{AA}^{\prime} \mathrm{BO}_{3}, \mathrm{ABB}^{\prime} \mathrm{O}_{3}$ and $\mathrm{AA}^{\prime} \mathrm{BB}^{\prime} \mathrm{O}_{3}$ perovskites are given along with the related magnetic moments with ESI. $\dagger$

Perovskite surfaces were modeled using the (010) facet with AO-termination, which is geometrically symmetric with the 
(001) and (100) facet, dependent on composition, based on previous work suggesting that this is the thermodynamically most stable surface. ${ }^{42}$ The surface models contained the same number of atoms as the bulk models, that is with $\mathrm{A}_{2} \mathrm{~B}_{2} \mathrm{O}_{6}$ stoichiometry, of which the upper $\mathrm{ABO}_{3}(010)$ layer parallel to the surface was allowed to relax, while the lower $\mathrm{ABO}_{3}$ layer was constrained to the bulk geometry. All surface models were periodically repeated in the directions parallel to the surface, used $10 \AA$ of vacuum perpendicular to the surface, and employed a $k$-point sampling of $4 \times 4 \times 1$. To model reduced perovskite surfaces, one third of the stoichiometric lattice oxygen in the upper surface layer was removed yielding $\mathrm{A}_{2} \mathrm{~B}_{2} \mathrm{O}_{5}(010)$ stoichiometry with $\delta=0.5$.

The Gibbs free energy of oxygen vacancy formation $\left(\Delta G_{\mathrm{v}}[\mathrm{O}]\right)$ was computed with: ${ }^{22}$

$$
\Delta G_{\mathrm{v}}[\mathrm{O}]=G_{\mathrm{v}}-\left(G_{\mathrm{s}}-G_{\mathrm{O}}^{\mathrm{r}}\right)
$$

with $G_{\mathrm{v}}$ and $G_{\mathrm{s}}$ being the Gibbs free energies of the perovskite surface models with and without oxygen vacancies, and with $G_{\mathrm{O}}^{\mathrm{r}}$ being the reference energy of the liberated lattice oxygen, taken as the energy difference of stable $\mathrm{H}_{2} \mathrm{O}$ and $\mathrm{H}_{2}$ in the gas phase. Negative free energies correspond to exergonic reactions.

We employ the standard enthalpy of bulk metal oxide decomposition into the metals and $\mathrm{O}_{2}$, computed at $298 \mathrm{~K}$ and 1 bar total pressure $\left(\Delta \bar{h}^{\circ}\right)$, as a descriptor of redox-activity. For a limited number of mostly stoichiometric binary metal oxides, $\Delta \bar{h}^{\circ}$ can be computed from tabulated thermochemical data. ${ }^{59}$ To estimate $\Delta \bar{h}^{\circ}$ for the investigated perovskites without the need for resource-demanding phonon calculations to determine solid-state entropies, we utilized previously established scaling relations describing the correction between $\Delta \bar{h}^{\circ}$ and $\Delta G_{\mathrm{v}}[\mathrm{O}] .{ }^{42}$ As discussed in detail with ESI, $\dagger$ we employed:

$$
\Delta G_{\mathrm{v}}[\mathrm{O}]=4.491 \times 10^{-3} \frac{\mathrm{eV}}{\mathrm{kJ} \mathrm{mol}_{\mathrm{O}_{2}}{ }^{-1}} \Delta \bar{h}_{\mathrm{O}_{2}}^{\circ}-8.164 \times 10^{-1} \mathrm{eV}
$$

Thermodynamic properties obtained using eqn (5) are per mole $\mathrm{O}_{2}$. Detailed descriptions of converting the DFT-derived $\Delta G_{\mathrm{v}}[\mathrm{O}]$ values into Gibbs free energy changes at a specific set of reaction temperature and $p_{\mathrm{O}_{2}}$, and of the utilized reference energies are provided with ESI. $\dagger$

\subsection{Sample preparation}

All perovskites were synthesized with a modified Pechini method, using stoichiometric amounts of $\mathrm{La}\left(\mathrm{NO}_{3}\right)_{3} \cdot \mathrm{H}_{2} \mathrm{O}$ (Sigma Aldrich, 99.999\%), $\mathrm{Sr}\left(\mathrm{NO}_{3}\right)_{2}$ (Sigma Aldrich, 98\%), $\mathrm{Mn}\left(\mathrm{NO}_{3}\right)_{2}$ $\cdot 4 \mathrm{H}_{2} \mathrm{O}$ (Alfa Aesar, 98\%), $\mathrm{Al}\left(\mathrm{NO}_{3}\right)_{3} \cdot 9 \mathrm{H}_{2} \mathrm{O}$ (Alfa Aesar, 98\%), $\mathrm{Ca}\left(\mathrm{NO}_{3}\right)_{2} \cdot 4 \mathrm{H}_{2} \mathrm{O}$ (Alfa Aesar, 99\%), $\mathrm{Y}\left(\mathrm{NO}_{3}\right)_{3} \cdot 6 \mathrm{H}_{2} \mathrm{O}$ (Alfa Aesar, 99.9\%), $\mathrm{Co}\left(\mathrm{NO}_{3}\right)_{2} \cdot 6 \mathrm{H}_{2} \mathrm{O}$ (Sigma Aldrich, 98\%), $\mathrm{Ni}\left(\mathrm{NO}_{3}\right)_{2} \cdot 6 \mathrm{H}_{2} \mathrm{O}$ (Sigma Aldrich, 97\%), $\mathrm{C}_{2} \mathrm{H}_{6} \mathrm{O}$ (Alcosuisse, >96.1\% vol) and $\mathrm{C}_{6} \mathrm{H}_{8} \mathrm{O}_{7}$ (Fluka Chemika, $\geq 99.5 \%$ ). The ratio between the metal cations and citric acid was $2: 3 . \mathrm{SrTiO}_{3}(99 \%)$ was purchased from Sigma-Aldrich. Solid products were ground using mortar and pestle and sintered for $24 \mathrm{~h}$ in air at $1573 \mathrm{~K}$ with heating and cooling at $2.5 \mathrm{~K} \mathrm{~min}^{-1}$.

\subsection{Solid-state analysis}

RT-XRD and HT-XRD were performed in the Bragg Brentano geometry using $\mathrm{Cu} \mathrm{K} \alpha$ radiation $\left(20-80^{\circ} 2 \theta, 0.01^{\circ} \mathrm{min}^{-1}\right.$ scan rate, $45 \mathrm{kV} / 20 \mathrm{~mA}$ output, PANalytical/X'Pert MPD/DY636, Philips). The HT-XRD experiments were performed at 673, 873, 1073 , and $1273 \mathrm{~K}$, with heating at $10 \mathrm{~K} \mathrm{~min}^{-1}$ and a gas flow of $1 \mathrm{~L} \mathrm{~min}^{-1}$. All volumes are given at standard conditions, here 1 bar and $20{ }^{\circ} \mathrm{C}$. Before each HT-XRD scan, the temperature was held for one hour to establish thermodynamic equilibrium. TEM analyses were performed for $\mathrm{SrTiO}_{3}, \mathrm{SrCoO}_{3}, \mathrm{SrMnO}_{3}$, and $\mathrm{BaCoO}_{3}$ employing the high angle annular dark field detector used in scanning transmission electron microscopy (HAADF STEM) imaging mode and complemented by elemental distribution analyses using the SuperX EDX system of a FEI TalosF200X instrument, operated at $200 \mathrm{kV}$ acceleration voltage. The surfaces of $\mathrm{SrTiO}_{3}, \mathrm{BaCoO}_{3}, \mathrm{SrMnO}_{3}$, and $\mathrm{SrCoO}_{3}$ were sampled at 17, 8, 9, and 9 different locations, respectively.

\subsection{Thermal analysis}

Perovskite reduction and oxidation were performed using a TGA (Setaram Setsys Evolution) to measure oxygen nonstoichiometries $(\delta)$. Samples with a mass of about $100 \mathrm{mg}$ were finely ground and placed into an $\mathrm{Al}_{2} \mathrm{O}_{3}$ crucible which was covered with a platinum sheet. Heating and cooling were at 10 and $20 \mathrm{~K} \mathrm{~min}^{-1}$, respectively. Reduction was carried out at 1573

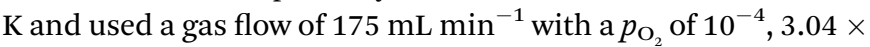
$10^{-4}$, and $5.07 \times 10^{-4}$ bar $\mathrm{O}_{2}$, adjusted using a mixture of 500 ppm $\mathrm{O}_{2}$ in $\mathrm{Ar}$ and pure Ar. Reduction conditions were held for 60 min. Oxidation was carried out at 873, 1073, and $1273 \mathrm{~K}$ and used a gas flow of $192 \mathrm{~mL} \mathrm{~min}{ }^{-1}$ with a $p_{\mathrm{O}_{2}}$ of $1.88 \times 10^{-21}, 3.79$ $\times 10^{-15}$, and $7.75 \times 10^{-11}$ bar, respectively. These $p_{\mathrm{O}_{2}}$ values correspond to $1 \% \mathrm{CO}$ in $\mathrm{CO}_{2}$, simulating a typical gas composition at the end of the oxidation run in a solar receiver-reactor. ${ }^{6}$ To assess the sensitivity of the perovskites to the gas composition during oxidation, oxidation was carried out also in pure $\mathrm{CO}_{2}$ and 873,1073 , and $1273 \mathrm{~K}$, corresponding to a $p_{\mathrm{O}_{2}}$ of $3.67 \times$ $10^{-9}, 4.63 \times 10^{-7}$, and $1.27 \times 10^{-5}$ bar $\mathrm{O}_{2}$. Oxidation conditions were held for $80 \mathrm{~min}$. For complete re-oxidation before and after each reduction and oxidation experiment, the samples were exposed for $30 \mathrm{~min}$ at $873 \mathrm{~K}$ to a gas flow of $175 \mathrm{~mL} \mathrm{~min}^{-1}$ with 0.2 bar $\mathrm{O}_{2}$. The gas composition at the TGA outlet was monitored with a gas chromatograph (GC, CP-4900 System, Agilent Technologies). To account for buoyancy effects, blank runs were conducted for all specific measurement conditions without the perovskite samples.

\section{Acknowledgements}

We gratefully acknowledge the financial support by the Swiss National Science Foundation (Ambizione Energy Grant No. 166883), the Helmholtz-Gemeinschaft Deutscher Forschungszentren (Virtuelles Institut SolarSyngas), and the European Research Council under the European Union's ERC Advanced Grant (SUNFUELS-No. 320541). The DFT calculations were performed at the High-Performance Computation cluster of ETH Zürich. 


\section{References}

1 M. Romero and A. Steinfeld, Energy Environ. Sci., 2012, 5, 9234.

2 W. C. Chueh and S. M. Haile, Chemsuschem, 2009, 2, 735.

3 W. C. Chueh and S. M. Haile, Philos. Trans. R. Soc., A, 2010, 368, 3269.

4 E. A. Fletcher, J. Sol. Energy Eng., 2001, 123, 63.

5 J. R. Scheffe and A. Steinfeld, Mater. Today, 2014, 17, 341348.

6 D. Marxer, P. Furler, J. Scheffe, H. Geerlings, C. Falter, V. Batteiger, A. Sizmann and A. Steinfeld, Energy Fuels, 2015, 29, 3241.

7 T. Nakamura, Sol. Energy, 1977, 19, 467.

8 T. Kodama, Prog. Energy Combust. Sci., 2003, 29, 567.

9 M. Roeb, M. Neises, N. Monnerie, F. Call, H. Simon, C. Sattler, M. Schmucker and R. Pitz-Paal, Materials, 2012, 5, 2015.

10 G. P. Smestad and A. Steinfeld, Ind. Eng. Chem. Res., 2012, 51, 11828.

11 Z. Wang, R. R. Roberts, G. F. Naterer and K. S. Gabriel, Int. J. Hydrogen Energy, 2012, 37, 16287.

12 W. C. Chueh, A. H. McDaniel, M. E. Grass, Y. Hao, N. Jabeen, Z. Liu, S. M. Haile, K. F. McCarty, H. Bluhm and F. El Gabaly, Chem. Mater., 2012, 24, 1876.

13 S. Ackermann, J. R. Scheffe and A. Steinfeld, J. Phys. Chem. C, 2014, 118, 5216.

14 S. Abanades, A. Legal, A. Cordier, G. Peraudeau, G. Flamant and A. Julbe, J. Mater. Sci., 2010, 45, 4163.

15 A. Le Gal, S. Abanades and G. Flamant, Energy Fuels, 2011, 25, 4836.

16 P. Singh and M. S. Hegde, Chem. Mater., 2010, 22, 762.

17 H. Kaneko, T. Miura, H. Ishihara, S. Taku, T. Yokoyama, H. Nakajima and Y. Tamaura, Energy, 2007, 32, 656.

18 Q. L. Meng, C. I. Lee, T. Ishihara, H. Kaneko and Y. Tamaura, Int. J. Hydrogen Energy, 2011, 36, 13435.

19 S. G. Huang, L. Li, J. Vleugels, P. L. Wang and O. Van der Biest, J. Eur. Ceram. Soc., 2003, 23, 99.

20 K. Otsuka, M. Hatano and A. Morikawa, Inorg. Chim. Acta, 1985, 109, 193.

21 S. Abanades, P. Charvin, G. Flamant and P. Neveu, Energy, 2006, 31, 2805.

22 P. Furler, J. Scheffe, M. Gorbar, L. Moes, U. Vogt and A. Steinfeld, Energy Fuels, 2012, 26, 7051.

23 W. C. Chueh, C. Falter, M. Abbott, D. Scipio, P. Furler, S. M. Haile and A. Steinfeld, Science, 2010, 330, 1797.

24 A. H. McDaniel, E. C. Miller, D. Arifin, A. Ambrosini, E. N. Coker, R. O'Hayre, W. C. Chueh and J. H. Tong, Energy Environ. Sci., 2013, 6, 2424.

25 R. J. Panlener, R. N. Blumenthal and J. E. Garnier, J. Phys. Chem. Solids, 1975, 36, 1213.

26 C. K. Yang, Y. Yamazaki, A. Aydin and S. M. Haile, J. Mater. Chem. A, 2014, 2, 13612.

27 J. R. Scheffe, D. Weibel and A. Steinfeld, Energy Fuels, 2013, 27, 4250 .

28 A. Demont, S. Abanades and E. Beche, J. Phys. Chem. C, 2014, 118, 12682.
29 S. Dey, B. S. Naidu, A. Govindaraj and C. N. R. Rao, Phys. Chem. Chem. Phys., 2015, 17, 122.

30 A. Demont and S. Abanades, RSC Adv., 2014, 4, 54885.

31 T. Cooper, J. R. Scheffe, M. E. Galvez, R. Jacot, G. Patzke and

A. Steinfeld, Energy Technol., 2015, 3, 1130.

32 M. Takacs, M. Hoes, M. Caduff, T. Cooper, J. R. Scheffe and A. Steinfeld, Acta Mater., 2016, 700.

33 M. Ezbiri, M. Takacs, D. Theiler, R. Michalsky and A. Steinfeld, J. Mater. Chem. A, 2017, 5, 4172-4182.

34 L. Nalbandian, A. Evdou and V. Zaspalis, Int. J. Hydrogen Energy, 2009, 34, 7162.

35 A. Demont and S. Abanades, J. Mater. Chem. A, 2015, 3, 3536. 36 A. H. Bork, M. Kubicek, M. Struzik and J. L. M. Rupp, J. Mater. Chem. A, 2015, 3, 15546.

37 S. Dey, B. S. Naidu and C. N. R. Rao, Chem.-Eur. J., 2015, 21, 7077.

38 P. M. Geffroy, J. Fouletier, N. Richet and T. Chartier, Chem. Eng. Sci., 2013, 87, 408.

39 A. A. Emery, J. E. Saal, S. Kirklin, V. I. Hegde and C. Wolverton, Chem. Mater., 2016, 28, 5621.

40 A. M. Deml, A. M. Holder, R. P. O'Hayre, C. B. Musgrave and V. Steyanovic, J. Phys. Chem. Lett., 2015, 6, 1948.

41 A. M. Deml, V. Stevanovic, C. L. Muhich, C. B. Musgrave and R. O'Hayre, Energy Environ. Sci., 2014, 7, 1996.

42 R. Michalsky, V. Botu, C. M. Hargus, A. A. Peterson and A. Steinfeld, Adv. Energy Mater., 2014, 4, 1401082.

43 F. Calle-Vallejo, J. I. Martinez, J. M. Garcia-Lastra, M. Mogensen and J. Rossmeisl, Angew. Chem., 2010, 49, 7699.

44 B. Meredig and C. Wolverton, Phys. Rev. B: Condens. Matter Mater. Phys., 2009, 80, 245119.

45 M. T. Curnan and J. R. Kitchin, J. Phys. Chem. C, 2014, 118, 28776-28790.

46 M. Ezbiri, K. M. Allen, M. E. Gàlvez, R. Michalsky and A. Steinfeld, Chemsuschem, 2015, 8, 1966.

47 M. Ghiasi, A. Malekzadeh and Y. Mortazavi, "Effect of the cation of site A on the formation of (Ce, La or $\mathrm{Sr}$ ) $\mathrm{CoO}_{3}$ nano-perovskites", presented at Proceedings of the 4th International Conference on Nanostructures (ICNS4), 2012.

48 K. Umemoto, Y. Seto and Y. Masuda, Thermochim. Acta, 2005, 431, 117.

49 M. Takacs, J. R. Scheffe and A. Steinfeld, Phys. Chem. Chem. Phys., 2015, 17, 7813.

50 HSC Chemistry 5.0, Outokumpu Research Oy, 2002.

51 C. J. H. Jacobsen, S. Dahl, B. S. Clausen, S. Bahn, A. Logadottir and J. K. Norskov, J. Am. Chem. Soc., 2001, 123, 8404 .

52 J. Enkovaara, C. Rostgaard, J. J. Mortensen, J. Chen, M. Dulak, L. Ferrighi, J. Gavnholt, C. Glinsvad, V. Haikola, H. A. Hansen, H. H. Kristoffersen, M. Kuisma, A. H. Larsen, L. Lehtovaara, M. Ljungberg, O. LopezAcevedo, P. G. Moses, J. Ojanen, T. Olsen, V. Petzold, N. A. Romero, J. Stausholm-Moller, M. Strange, G. A. Tritsaris, M. Vanin, M. Walter, B. Hammer, H. Hakkinen, G. K. H. Madsen, R. M. Nieminen, J. Nørskov, M. Puska, T. T. Rantala, J. Schiotz, 
K. S. Thygesen and K. W. Jacobsen, J. Phys.: Condens. Matter, 2010, 22, 253202.

53 J. J. Mortensen, L. B. Hansen and K. W. Jacobsen, Phys. Rev. B: Condens. Matter Mater. Phys., 2005, 71, 035109.

54 S. R. Bahn and K. W. Jacobsen, Comput. Sci. Eng., 2002, 4, 56.

55 B. Hammer, L. B. Hansen and J. K. Nørskov, Phys. Rev. B: Condens. Matter Mater. Phys., 1999, 59, 7413.
56 A. J. Medford, J. Wellendorff, A. Vojvodic, F. Studt, F. AbildPedersen, K. W. Jacobsen, T. Bligaard and J. K. Norskov, Science, 2014, 345, 197.

57 M. García-Mota, A. Vojvodic, H. Metiu, I. C. Man, H. Y. Su, J. Rossmeisl and J. K. Nørskov, ChemCatChem, 2011, 3, 1607.

58 R. Michalsky, D. Neuhaus and A. Steinfeld, Energy Technol., 2015, 3, 784.

59 I. Barin, Thermochemical Data of Pure Substances, 1993. 